\title{
Effects of the 1997-1998 El Niño on the exchange of the northern Gulf of California
}

\author{
Manuel López \\ Departamento de Oceanografia Física, Centro de Investigación Científica y de Educación Superior de Ensenada (CICESE), \\ Ensenada, Mexico
}

Luis Zamudio

Center for Ocean-Atmosphere Prediction Studies, Florida State University, Tallahassee, Florida, USA

Francisco Padilla

Estación de Investigación Oceanográfica de Ensenada, Secretaría de Marina, Ensenada, Mexico

Received 3 September 2004; revised 29 May 2005; accepted 17 August 2005; published 9 November 2005.

[1] We analyze sea level and transports in the Gulf of California from two large-scale, high-resolution numerical models: the Naval Research Laboratory Layered Ocean Model and the Hybrid Coordinate Ocean Model. Sea level from both models correlates well with sea surface height from a nearby TOPEX track and subsurface pressure measured in the northern gulf during 1997-1998. An 8-year mean (1993-2000) section of the modeled meridional velocity at the mouth of the gulf is in good qualitative agreement with observations, showing a localized near-surface outflow on the Baja California side. The 8-year mean, laterally integrated modeled near-surface transport at the mouth of the gulf shows an opposite direction for both models. During the 1997-1998 El Niño, however, both models show a similar structure with increased inflow in the upper $100 \mathrm{~m}$ and an increased outflow in the underlying layer to about $500 \mathrm{~m}$ depth. The modeled surface transport also shows increased inflow in the northern gulf. The modeled incoming surface transport from both models during El Niño is negatively correlated to near-bottom currents measured at a sill in the northern gulf. This measured near-bottom current has previously been shown to constitute part of the strong, localized incoming flow from the Pacific Ocean. The negative correlation strongly suggests that the anomalous incoming surface flow at the mouth of the gulf inhibited the normal near-surface outflow of the northern Gulf of California water. This, in turn, inhibited the normal deeper inflow, entering the northern gulf from the Pacific Ocean. These anomalies apparently increased the residence time of the waters in the northern gulf. They are consistent with anomalously high near-bottom salinities found during 1997-1998. Hydrographic data for July 1997 also show an anomalous low salinity surface water, which is most likely associated with advection of tropical waters from the Pacific Ocean.

Citation: López, M., L. Zamudio, and F. Padilla (2005), Effects of the 1997-1998 El Niño on the exchange of the northern Gulf of California, J. Geophys. Res., 110, C11005, doi:10.1029/2004JC002700.

\section{Introduction}

[2] It has been 20 years since Baumgartner and Christensen [1985] demonstrated that the interannual sea level variability of the Gulf of California is linked to the El Niño-Southern Oscillation (ENSO) phenomenon of the equatorial Pacific. They proposed that ENSO conditions at the mouth of the gulf should be a more intense autumn condition, whereby the Costa Rica Coastal Current (CRCC) is strong and extends to the mouth of the gulf. The surface layer at the mouth of the gulf, therefore, should be

Copyright 2005 by the American Geophysical Union. 0148-0227/05/2004JC002700\$09.00 "invaded" by an anomalously strong CRCC, carrying tropical surface water, during ENSO years. The surface exchange in the upper $50 \mathrm{~m}$ of the gulf should then be with the tropical surface water carried by the stronger than normal CRCC. The anomalously high sea level and northward transport found at the mouth of the gulf during the 19971998 El Niño by Strub and James [2002a] support the ideas proposed by Baumgartner and Christensen [1985]. The sea surface height (SSH) "snapshots" and associated geostrophic velocities from June through August 1997, presented by Strub and James [2002b] are also consistent with poleward surface flow during the 1997-1998 El Niño (see their Figure 9).

[3] Using hydrographic observations and geostrophic currents, Bray [1988a] proposed a three-layer, along-gulf 


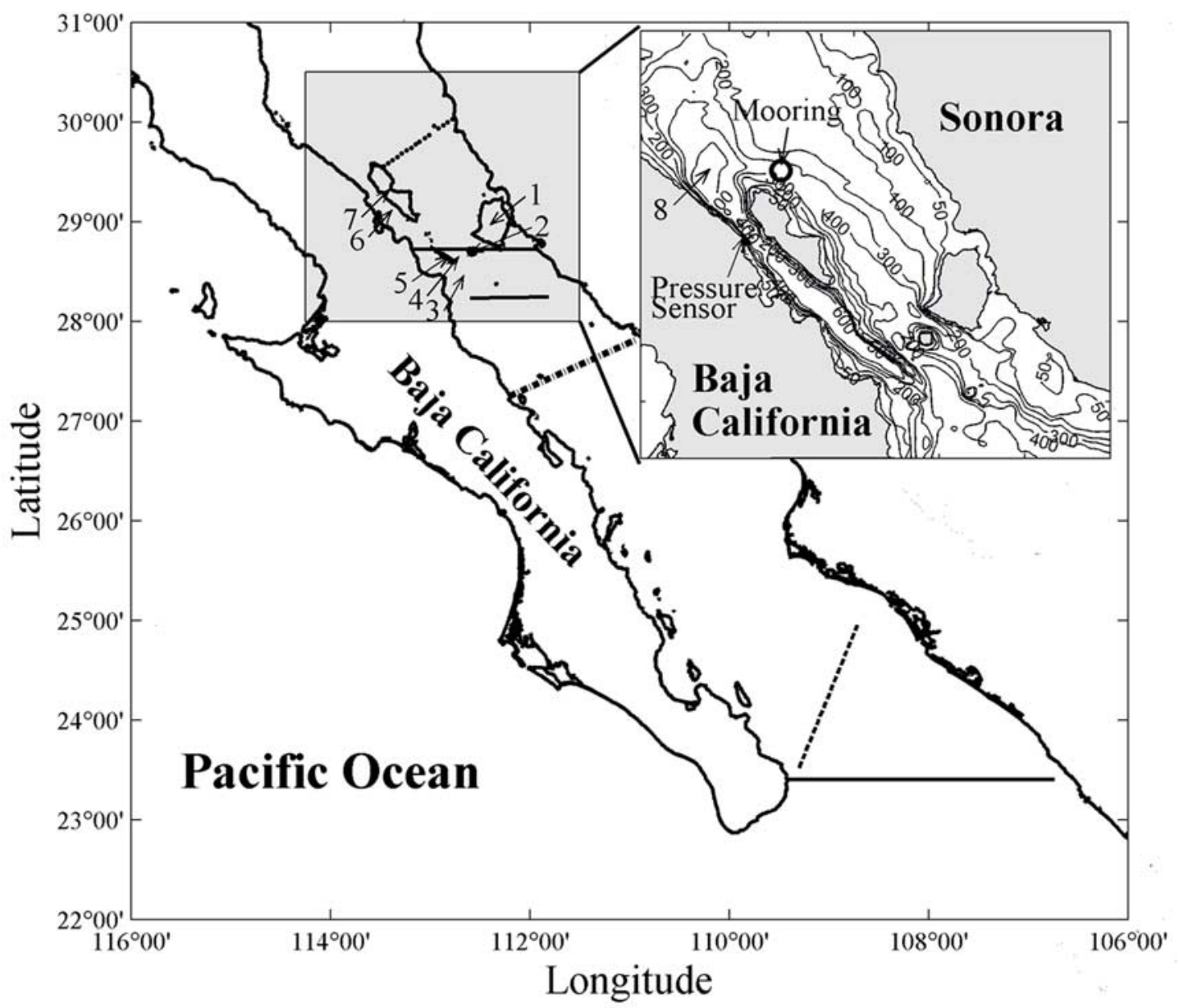

Figure 1. Map of the Gulf of California showing the TOPEX/Poseidon track (dashed line) and zonal lines at the mouth of the gulf and at $28.7^{\circ} \mathrm{N}$, where SSH and modeled data were considered. The zonal line just to the south of the mid-gulf islands marks the northernmost boundary of the NLOM model. The dash-dotted line in the central gulf marks the Guaymas-Sta. Rosalía section. Numbers in the region of the islands refer to: 1, Tiburón I.; 2, San Esteban I.; 3, San Lorenzo sill; 4, San Esteban sill; 5, San Lorenzo I.; 6, Ballenas Channel; and 7, Angel de la Guarda I. CTD stations occupied in July 1997 are marked by dots in the northern gulf. The mooring at the sill, the pressure sensor in Ballenas Channel, Delfín Basin (8), and the bathymetry in meters are shown in the enlargement of the island region.

circulation of the upper $500 \mathrm{~m}$ at the central gulf (at the Guaymas-Sta. Rosalía line; see Figure 1). A 50-m surface layer presumably flows in the direction of the seasonally reversing winds. Below, to $250 \mathrm{~m}$ depth, there is an outward flow carrying relatively warm, salty Gulf of California water and a deeper inflow of fresher, colder water from the Pacific Ocean, presumably subsurface, subtropical water somewhat mixed with higher-salinity waters from the northern gulf [Bray, 1988b]. The mean circulation in the two lower layers constitutes the exchange between the northern and southern parts of the gulf. The exchange of the southern part of the gulf (south of the chain of islands marked by the presence of Tiburón Island, see Figure 1) with the Pacific Ocean is not restricted by any sill. However, the deepest exchange of the northern gulf is restricted by San Esteban sill, which has a depth of $600 \mathrm{~m}$. Therefore the exchange of the northern gulf with the southern part of the gulf as well as with the Pacific Ocean, should essentially follow the pattern proposed by Bray [1988a].

[4] Badan-Dangon et al. [1991] observed a strong nearbottom inflow through San Lorenzo sill (400 m depth) over the course of 20 days. López and Garcia [2003] (hereinafter LG) documented 8 months of a strong nearbottom current ( $23 \mathrm{~m}$ above the bottom), flowing persistently toward the head of the gulf at a sill located just northeast of the northern tip of Angel de la Guarda Island (see Figure 1) at a depth of $340 \mathrm{~m}$. Since the deep Ballenas Channel, located in the western part of the northern Gulf of California (NGC), is not connected to the eastern side of the NGC below 200 m, the deep inflow observed by LG must have passed through the deepest San Esteban sill. These current observations were taken during 1997-1998 and, to our knowledge, are the only current data available for the northern gulf during the 1997-1998 El Niño. These strong bottom flows, observed at two 
different sills [i.e., Badan-Dangon et al., 1991] (and LG), constitute part of the deep portion of the two-layer exchange that was originally proposed by Bray [1988a]. Given the results discussed above (i.e., the increased surface transport into the gulf during ENSO years and the two-layer exchange in the northern gulf with nearsurface outflow and deeper inflow), it is natural to propose the possibility that the exchange pattern of the northern gulf is reduced or reversed during ENSO years.

[5] In this article, we use results from two high-resolution, large-scale numerical ocean models as well as observations to show that, indeed, there was an anomalous northward surface transport into the gulf. In addition, this transport correlated negatively with the deep inflow in the northern gulf reported by LG during 1997-1998. For the purposes of this study, it is crucial to use results from largescale numerical models that include the whole Pacific Ocean and can, therefore, simulate reasonably well the 1997-1998 El Niño response in the gulf. In the next section, we describe the models and observations used. We then describe and discuss the results in sections 3 and 4, respectively. In the final section, we present some concluding remarks.

\section{Models and Observations}

\subsection{Models}

[6] We use results from a simulation of the Naval Research Laboratory (NRL) Layered Ocean Model (NLOM) at the mouth of the gulf of California. The NLOM is a nearly global $\left(72^{\circ} \mathrm{S}\right.$ to $\left.65^{\circ} \mathrm{N}\right)$, eddy resolving $\left(1 / 16^{\circ}\right)$ hindcast ocean model. We use a six-layer simulation, incorporating data assimilation of sea surface temperature (SST) and sea surface height (SSH) satellite data, which spans an 8-year period from 1993 to 2000. The mean thickness of the layers of the NLOM at the mouth of the gulf are 56, 55, $391,625,721$, and $1563 \mathrm{~m}$, respectively. The model is forced with 6-hourly winds and daily averaged heat fluxes from the Fleet Numerical Meteorology and Oceanography Center's Navy Operational Global Atmospheric Prediction System (NOGAPS). The model uses the 200-m isobath as the coast and a modified version of ETOPO5 [National Oceanic and Atmospheric Administration, 1986] for bathymetry, which is only present in the lowest layer. The model includes roughly half of the Gulf of California, and its northern boundary in the gulf is located just south of the mid-gulf islands (see Figure 1). As will be seen below, this does not constitute a limitation for the strong remotely forced ENSO signal, propagating from the equator. Further details of the model are given by Rhodes et al. [2002], Zamudio et al. [2002], and Smedstad et al. [2003]. Metzger et al. [1998] describe the ability of NLOM in simulating the propagation of the 19971998 El Niño sea level signals from the equator to the North Pacific.

[7] We also use results from the HYbrid Vertical Coordinate Ocean Model (HYCOM), which is isopycnal in open stratified ocean, terrain following in shallow coastal regions, and $z$-level in the mixed layer and unstratified regions. This generalized vertical coordinate approach is dynamic in space and time via the layered continuity equation that allows a dynamic transition between the coordinate types. HYCOM was developed from the Miami Isopycnic
Coordinate Ocean Model (MICOM) using the theoretical foundations for implementing a hybrid coordinate system [Bleck, 2002]. The eddy-resolving $\left(1 / 12^{\circ}\right.$ equatorial resolution) Pacific HYCOM domain extends from $20^{\circ} \mathrm{S}$ to $65.8^{\circ} \mathrm{N}$ and from $109.1^{\circ} \mathrm{E}$ to $77.2^{\circ} \mathrm{W}$. The model is forced with daily averaged heat fluxes and 6-hourly 10-m winds from the European Centre for Medium-Range Weather Forecasts $(E C M W F)$ [1994] for the period 1979-2003. In addition, the model includes realistic bottom topography and coastline geometry, which are based on a modified version of the $1 / 30^{\circ}$ NRL DBDB2 topography [http://www7320.nrlssc. navy.mil/DBDB2 WWW]. The model uses the $10-\mathrm{m}$ isobath as a land-sea boundary, includes 19 vertical coordinate layers at the mouth of the gulf, allows isopycnals to intersect sloping topography by allowing zero thickness layers, and does not include ocean data assimilation. The mean thickness of the layers of the HYCOM at the mouth of the gulf are $3,3,5,12,18,21,15,31,60,81,86,95,115$, $151,225,252,395,678$, and $587 \mathrm{~m}$, respectively. Unlike the NLOM, the HYCOM includes the northern gulf. Furthermore, the HYCOM has a coastline and bathymetry, which are much more realistic than those used by the NLOM. Two recent studies have used the HYCOM results in the Gulf of California to study the ocean response to hurricane Juliette [Metzger et al., 2003] and the seasonal cycle [Zamudio et al., 2003].

[8] Model results used here include sea level at a TOPEX/Poseidon track near the entrance of the gulf as well as sea level, meridional velocity, and transport at a zonal line across the mouth of the gulf. We also use the HYCOM transport at a zonal line across the northern gulf at $28.7^{\circ} \mathrm{N}$ (see Figure 1). We use a common 8-year period from 1993 to 2000 for the long-term average of modeled velocity and transport.

\subsection{Data}

[9] We compare the modeled sea level with TOPEX/ Poseidon (SSH) along the track mentioned above. The TOPEX/Poseidon (T/P) data span the period from January 1993 to March 2000. The data were interpolated into an along-track $5.9-\mathrm{km}$ regular grid, and a standard set of geophysical corrections [Subrahmanyam, 1998] was applied to the data. This comparison helps to verify that both models are reproducing sea level data at the entrance of the gulf reasonably well. This is particularly important for HYCOM, because it does not include data assimilation.

[10] The models' results are compared to measured data, including a year-long subsurface pressure (SSP) time series measured at the northern part of Ballenas Channel from April 1997 to April 1998 (see Figure 1). The SSP data were recorded with an AANDERAA WLR-7 (water level recorder) anchored to a dead weight at $12 \mathrm{~m}$ depth. The WLR-7 has an accuracy of $1.4 \mathrm{mb}$ and a resolution of $0.07 \mathrm{mb}$. No correction for stratification was made, but CTD measurements taken in the area show that it is negligible within the first $12 \mathrm{~m}$. Tide and diurnal period fluctuations were filtered with Godin's filter [Godin, 1972], which has a half power point of 96 hours. We also use velocities from a mooring located in the northern gulf at a 340-m-depth sill, which connects the relatively shallow Tiburón Basin (maximum depths of about $440 \mathrm{~m}$ ) to the southeast with the deeper, albeit smaller, Delfín Basin 

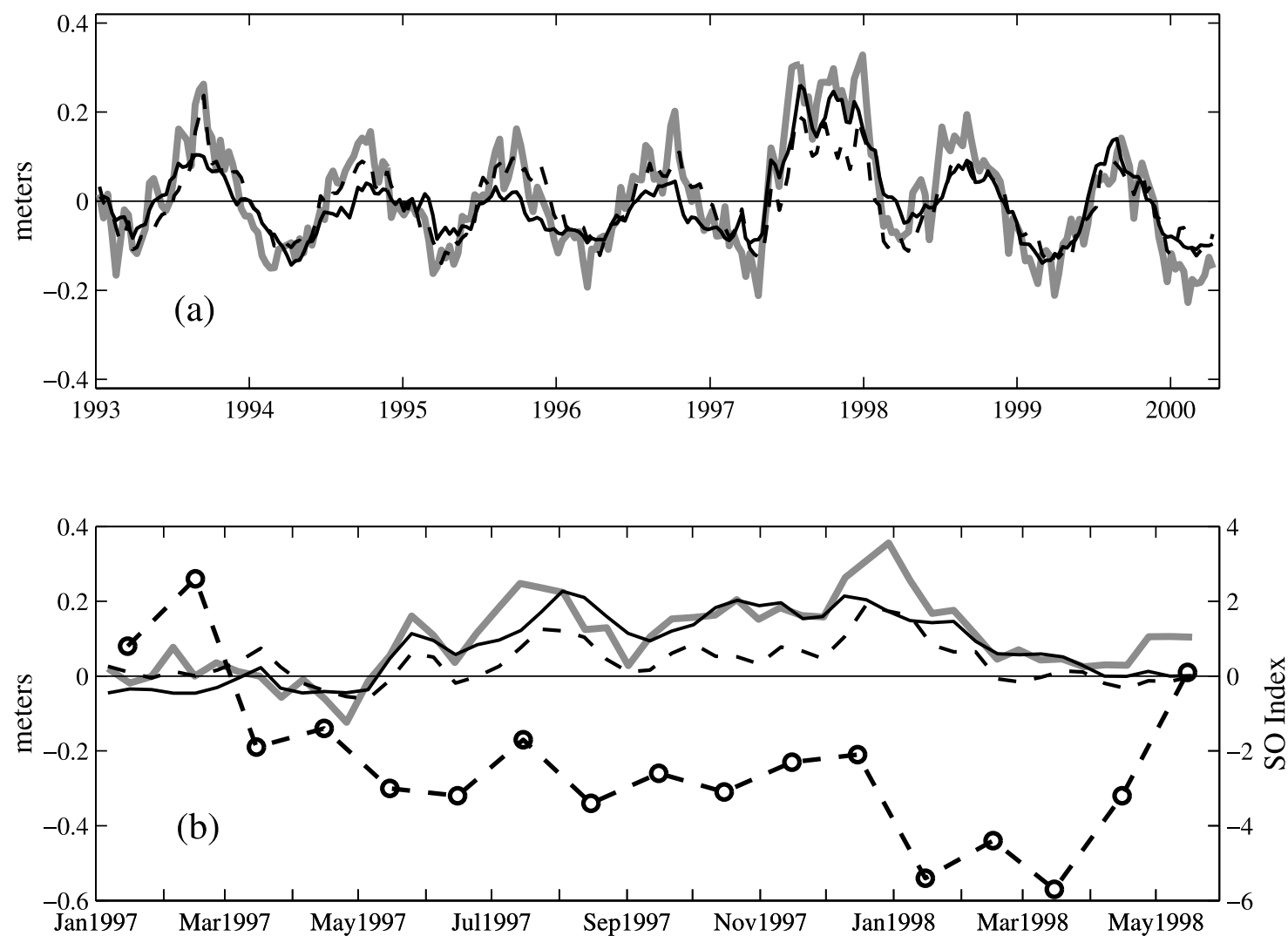

Figure 2. (a) Seven years of TOPEX/Poseidon SSH data (thick gray line), NLOM (dashed line), and HYCOM (thin black line) sea level data at the entrance of the gulf. (b) Same as in Figure 2a, except it is for the period covering the 1997-1998 El Niño event and the annual cycle has been removed. Also shown is the Southern Oscillation index (open circles and right axis).

(maximum depths of $\sim 800 \mathrm{~m}$ ) to the northwest (see Figure 1). The mooring had a $150-\mathrm{KHz}$ broadband ADCP at $280 \mathrm{~m}$ depth, measuring currents every $10 \mathrm{~m}$ and starting at $260 \mathrm{~m}$. The ADCP was deployed from July 1997 to March 1998. We complemented the mooring with an AANDERAA RCM-7 current meter at $317 \mathrm{~m}$ depth, $23 \mathrm{~m}$ above the bottom, in November. This current meter was deployed from November 1997 until July 1998, and it measured a persistent, strong bottom current toward the head of the gulf, with an average speed of $27 \mathrm{~cm} / \mathrm{s}$ during the 8-month deployment period. The mooring was recovered and redeployed in early November and late March, yielding data gaps of 4 and 3 days, respectively. In order to eliminate tidal currents with a minimum loss of data, velocities were averaged daily instead of filtered. A comparison of filtered and daily averaged data showed that both data sets were almost identical. The data gaps were interpolated by using splines. Further details and analysis of the SSP and velocity data, including an estimate of the bottom transport, are given by LG.

[11] In this study, we compare the modeled, surface transport in the northern gulf and at the mouth during the 1997-1998 El Niño with fluctuations in the exchange of the northern gulf with the Pacific Ocean. At the cross section, where the mooring was located, the exchange is best measured by the near-bottom currents at the sill, since the cross section near the bottom is greatly reduced and flow becomes concentrated (see Figures 2, 4 and 18 of
LG). Furthermore, the strength of the near-bottom current measured at this sill can be used as a measure of the northward flowing transport (LG). Therefore we only use the currents closest to the bottom for each period analyzed. We use the deepest bin of the ADCP at $260 \mathrm{~m}(80 \mathrm{~m}$ above the bottom) from July 1997 to March 1998 and the AANDERAA current meter at $317 \mathrm{~m}(23 \mathrm{~m}$ above the bottom) from November 1997 to July 1998. The cross section of the gulf becomes increasingly larger higher up in the water column, and currents are greatly influenced by mesoscale activity (LG). Actually, currents $17 \mathrm{~m}$ above the bottom are a much better indicator of the bottom transport, since currents $80 \mathrm{~m}$ above the bottom are not always within the strongly localized bottom current (see Figures 4 and 7 of LG).

[12] We will also use hydrographic data obtained in July 1997 at a cross section very near to where the mooring was placed (see Figure 1), as well as historic hydrographic data taken in the same region. The hydrographic data will be used to show the anomalous hydrographic conditions encountered in the northern gulf during the 1997-1998 El Niño.

\section{Results}

\subsection{Model Results}

[13] Slightly more than 7 years of along-track T/P SSH, averaged across the entrance of the gulf, and the 
(a) NLOM mean velocity

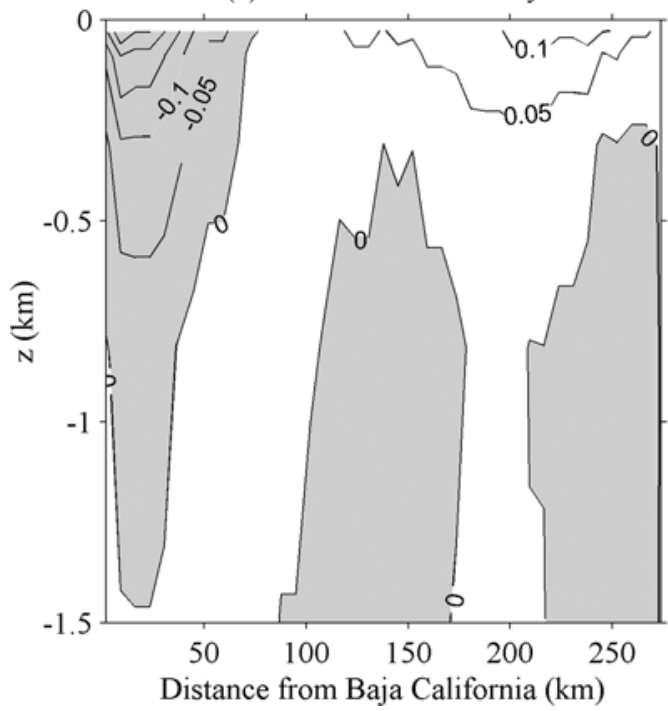

(b) HYCOM mean velocity

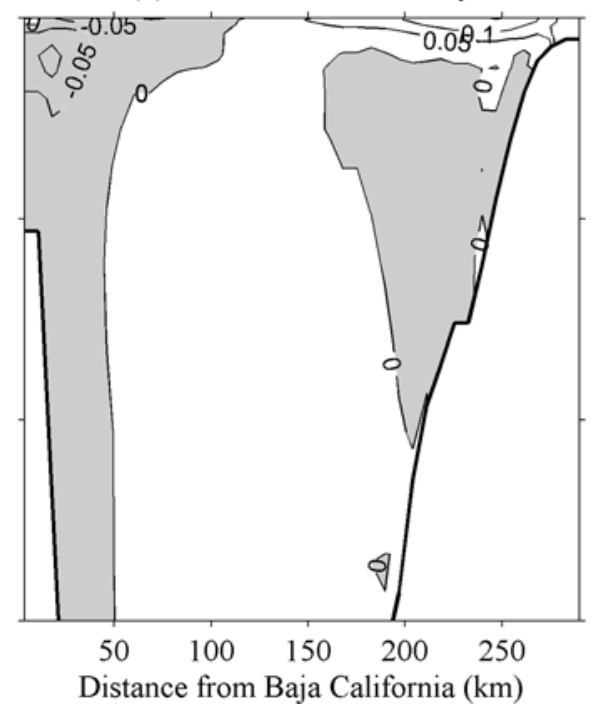

Figure 3. (a) Eight-year mean of the modeled meridional velocity from NLOM at a zonal section at the mouth of the gulf. Shaded areas correspond to flow out of the gulf. Only the upper $1500 \mathrm{~m}$ are shown. Contour interval is $0.05 \mathrm{~m} / \mathrm{s}$. (b) As in Figure 3a, but for HYCOM. The thick black line corresponds to the bottom in the HYCOM model.

corresponding sea level from the models are shown in Figure 2a. The T/P SSH data show a strong annual cycle, although some higher-frequency variability is also apparent. The T/P data clearly shows the anomalous SSH at the entrance of the gulf during the 1997-1998 El Niño event. The NLOM sea level captures very well the annual cycle as well as a significant portion of the higherfrequency variability. The HYCOM also captures the annual cycle reasonably well, although it appears somewhat underestimated from 1994 to 1996. The HYCOM also appears to underestimate the higher-frequency variability even more severely than NLOM during 1993 to 1996. However, the HYCOM sea level captures better the 1997-1998 El Niño event by underestimating it less during that event. Owing to the strong annual cycle, the correlation of these time series is 0.88 for HYCOM and 0.89 for NLOM.

[14] We also compared these two time series without the annual cycle, which was removed by a linear least squares fit to monthly values of an average year computed from the first 4 years of data (1993 to 1996). The correlation of these latter time series was still relatively high $(0.70$ for NLOM and 0.78 for HYCOM). A portion of the time series without the annual cycle, spanning the 1997-1998 ENSO event, is shown in Figure 2b. Note that the T/P series without the annual cycle is slightly larger than the original series from late December to May 1998 most of the time. This is due to the fact that the annual cycle is maximum on 15 September which, in turn, produces a greater anomaly during most of the 6 months following mid-December 1997 when the annual cycle is negative. Although the NLOM underestimates the $\mathrm{T} / \mathrm{P}$ SSH, the variability is well represented, as evidenced by a correlation of 0.79 between the time series appearing in Figure 2b. The HYCOM also represents the temporal variability well (correlation of 0.78 ) and estimates the magnitude better. Figure $2 \mathrm{~b}$ also compares the modeled and $\mathrm{T} / \mathrm{P}$ sea level with the southern oscillation index (SOI). The comparison indicates that the El Niño anomaly arrived in the Gulf of California roughly two months after its appearance in the equatorial Pacific. Figure $2 b$ also shows that the sea level anomaly at the mouth of the gulf had subsided by February 1998, although the SOI remained strong until about April. The fact that El Niño terminated earlier in the gulf has already been documented in other studies [Strub and James, 2002a; Lavín et al., 2003].

[15] The 8-year mean meridional velocity across the zonal line at the entrance of the gulf for both models is shown in Figure 3. To facilitate the comparison with the observations of Mascarenhas et al. [2004], we only plotted the upper $1500 \mathrm{~m}$. The magnitude of the modeled velocities below $1500 \mathrm{~m}$ are smaller than $0.02 \mathrm{~m} / \mathrm{s}$. The mean modeled near-surface velocity for both models shows a concentrated outflow along the Baja California side and a much broader inflow on the mainland side. The concentrated outflow is larger for the NLOM, but the inflow on the mainland side is of comparable magnitude for both models. The general pattern in Figure 3 is in good qualitative agreement with the direct velocity measurements reported by Collins et al. [1997] as well as with the mean geostrophic velocity reported by Mascarenhas et al. [2004], both of which were reported for the mouth of the gulf. The mean geostrophic velocity represents an average from nine cruises taken mainly during different months and years (see Figure 3a of Mascarenhas et al. [2004]). The mean geostrophic velocities also show a more concentrated subsurface outflow along the Baja 

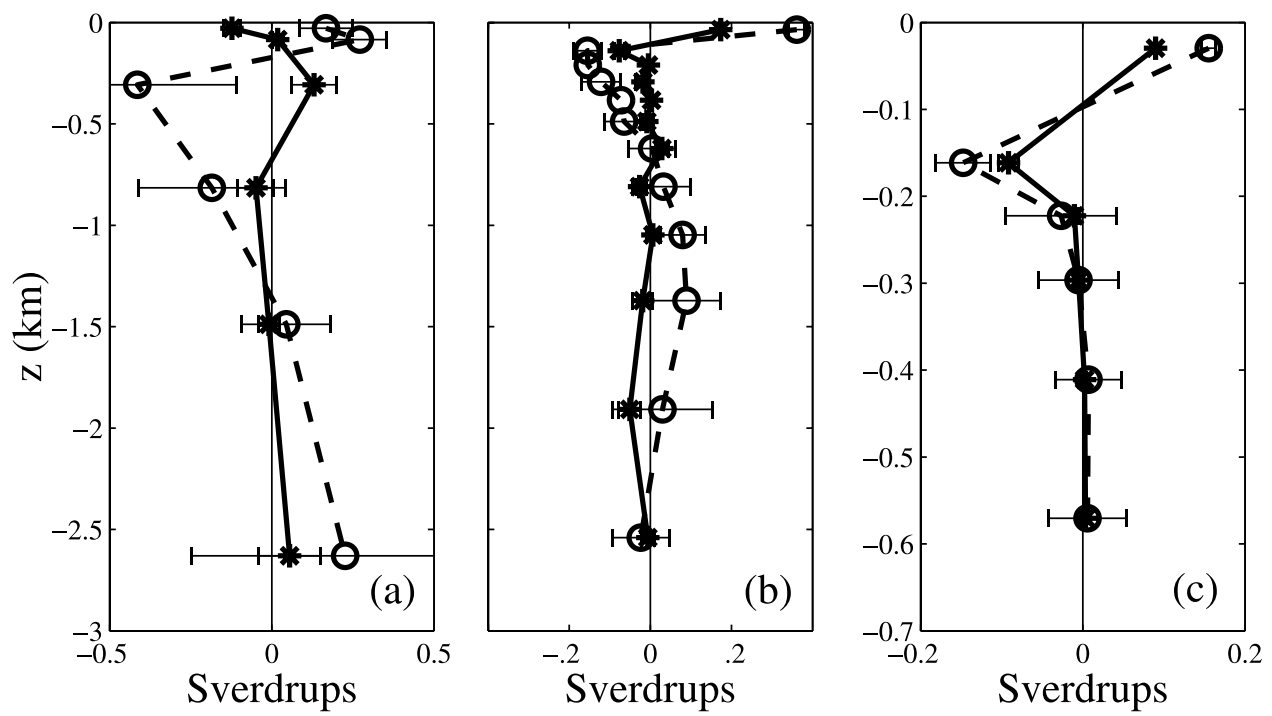

Figure 4. (a) Eight-year mean (1993-2000) of the laterally integrated NLOM transport at a zonal section at the mouth of the gulf (asterisks). Open circles correspond to the transport during the 19971998 El Niño (April 1997 to March 1998). Negative transports are toward the south (out of the gulf). (b) As in Figure 4a, but for HYCOM. (c) As in Figure 4b but for a section in the northern gulf, $740 \mathrm{~km}$ from the mouth. In Figures $4 b$ and $4 c$ the transport in the first eight layers of the HYCOM model (roughly the upper $100 \mathrm{~m}$ ) have been summed up. For clarity, in Figure 4b the error bars have been omitted in two layers of the model at 200 and $380 \mathrm{~m}$.

California side with two alternating bands of inflow and outflow, preceding the broad zone of inflow on the mainland side. Maximum geostrophic velocities in the subsurface outflow are slightly over $0.2 \mathrm{~m} / \mathrm{s}$. Therefore they are somewhat smaller than the velocities for the NLOM, but larger than the velocities for the HYCOM. The concentrated outflow for NLOM is maximum at the surface, whereas the HYCOM qualitatively reproduces the subsurface structure of this outflow. Note that the bottom topograpy of the NLOM is only present at the deepest layer and, therefore, is absent in Figure 3a.

[16] The 8-year mean, laterally integrated transport across the zonal lines at the entrance of the gulf and in the northern gulf, as well as the corresponding transport from April 1997 to March 1998, covering the El Niño event in the gulf, appear in Figure 4. The long-term NLOM transport shows a surface outflow in the first layer and an equivalent inflow in the third layer (centered at about $300 \mathrm{~m}$ depth), whereas the long-term transport is roughly reversed for the HYCOM, with inflow in the first eight layers (roughly to the same depth as the first two NLOM layers), and outflow to about $200 \mathrm{~m}$ depth. The transport of the first eight layers of the HYCOM model have been summed in Figures $4 b$ and $4 c$ in order to show more clearly the transport in the upper $100 \mathrm{~m}$ and the corresponding standard error bars. The transport is very weak deeper down to $600 \mathrm{~m}$ depth. However, the transport is similar in both models during the 1997-1998 El Niño. The NLOM shows a reversal of the long-term pattern, with inflow in the first two layers and a compensating strong outflow in the following two layers (see Figure 4a). For the HYCOM, the vertical structure of the transport during the 1997-1998 El Niño represents an enhancement of the long-term mean, with stronger inflow in the surface and stronger outflow to about $600 \mathrm{~m}$ depth (see Figure 4b). Note also that there is a relatively strong inflow in the deeper layers of both models at the mouth during the 19971998 El Niño. These deep flows will be discussed further in section 4. Figure $4 \mathrm{c}$ shows the corresponding integrated transport in the northern gulf in a zonal section, passing close to the islands (see Figure 1). Figure 4c also shows that the anomalous modeled surface transport into the gulf occurred all the way to the entrance of the northern gulf, at about $740 \mathrm{~km}$ from the mouth. As evidenced in Figure 4c, there is essentially no mean deep, near-bottom transport into the northern gulf. The HYCOM model, therefore, may not be accurately representing this part of the exchange. However, we believe that this does not affect our results, which depend on the anomalous surface transport entering the gulf. The latter appears to be accurately captured by both models. Note also that the surface transport decreases toward the northern gulf, implying a convergence at the surface.

\subsection{Model Results and Observations in the Northern Gulf}

[17] Low-frequency, sea level variability, propagating poleward from the equator, is known to travel as coastally trapped waves [e.g., Enfield and Allen, 1980; Clarke and Van Gorder, 1994]. Moreover, these poleward propagating oscillations in the intraseasonal band (periods from 30 to 90 days) are enhanced during El Niño events [Spillane et al., 1987; Kessler et al., 1995]. Therefore we considered daily modeled sea level, averaged across the zonal line at the mouth of the gulf (see Figure 1), as well as modeled sea level averaged in the $50 \mathrm{~km}$ closest to both coasts. These six time series (three for each model) were correlated with 
Table 1. Correlations and Lags Between Modeled Sea Level at the Mouth of the Gulf and Observed Subsurface Pressure in the Northern Gulf

\begin{tabular}{lcc}
\hline & NLOM & HYCOM \\
\hline Averaged & $0.70,6^{\mathrm{a}}$ & $0.66,0$ \\
CONT & $0.79,1$ & $0.79,0$ \\
BC & $0.66,6$ & $0.54,{ }^{\mathrm{b}} 6$ \\
\hline
\end{tabular}

${ }^{\mathrm{a}}$ Second number is the lag in days; positive lags are for observations leading the models.

${ }^{\mathrm{b}}$ Value is significant at a $95 \%$ confidence level.

observed subsurface pressure (SSP) at Ballenas Channel in the northern gulf, located about $940 \mathrm{~km}$ from the mouth. Maximum lagged correlations for the zonally averaged case, as well as for the time series averaged close to the continental side (CONT) and the Baja California side (BC), are listed in Table 1. We removed the annual cycle of all series. Using the formula given by Emery and Thomson [1997, p. 260], we estimated the minimum number of degrees of freedom at 14 . Therefore practically all correlations are significant at a $99 \%$ confidence level. Highest correlations of SSP are with modeled series averaged close to the continental side. However, lags between modeled series on the continental side and observations are not consistent with northward propagation, a fact that could easily be due to relatively small errors in the phase of the modeled series. Propagation around the gulf is consistent with the lags between the $\mathrm{BC}$ side and the observations as well as with the CONT, leading the BC side by 6 and 7 days for NLOM and HYCOM, respectively. These lags between modeled series are not shown in Table 1. Actually, the fact that lags between SSP at Ballenas Channel and BC are the same as those between the modeled series on both sides of the mouth of the gulf (6 days) is consistent with the modeled series being "ahead" of the observations by about 3 days. Significant correlations are confirmed by coherence functions (not shown) that produce relatively high and significant coherences for the low-frequency bands (roughly periods larger than 30 days). Modeled time series close to the mainland side and the subsurface pressure in the northern gulf are shown in Figure 5. Clearly, the modeled series reproduce very well the low-frequency events observed in the SSP of the northern gulf.
[18] Table 2 shows the maximum lagged correlations between the daily modeled surface meridional transport in the upper $100 \mathrm{~m}$, integrated across the mouth of the gulf and across a zonal line in the northern gulf with the near-bottom velocities in the northern gulf for the two periods considered. All correlations are for lags of 4 days or less, with modeled series leading observations. Although most correlations are somewhat low, they are all statistically significant at a $95 \%$ confidence level, with effective degrees of freedom ranging from 37 for the largest correlation to 73 for the lowest. The observed velocity time series during both periods, together with the NLOM transport during the first period and with the HYCOM transport in the northern gulf during the second period, are shown in Figure 6. All observed currents have been rotated to principal axes, coinciding roughly with the axis of the gulf, and are positive toward the head of the gulf. Note that the time axes are different in the two panels of Figure 6, even though they overlap from November 1997 to March 1998. Although we do not possess an entire year of observations at the same depth, an annual cycle was not apparent. For the modeled transports, the annual cycle explained a very insignificant percentage of the variance. The negative correlation found in all cases is visually apparent in both panels of Figure 6 . This indicates that an increased surface transport into the gulf is related to a weakening of the northward flowing, near-bottom velocities at this sill in the northern gulf for the period ranging from July 1997 to July 1998. Note that the near-bottom current, $23 \mathrm{~m}$ above the bottom, flows strongly and persistently toward the head of the gulf (see Figure 6b). Moreover, there is only one reversal in which the current flows toward the mouth of the gulf during December 1997.

[19] Since most of the correlations were not high, we sought to support further the negative correlations by estimating coherences between the modeled surface transports and the observed near-bottom velocities. Our observed series are not very long (260 and 278 days for the first and second periods, respectively) so we divided the time series into four segments which barely resolves periods around 60 days with 8 degrees of freedom and estimated coherences using the Welch periodogram method. Coherence plots between the time series, appearing in Figure 6, are shown in Figure 7. They show that significant coherences occur at low frequencies. Figure 7 a shows significant

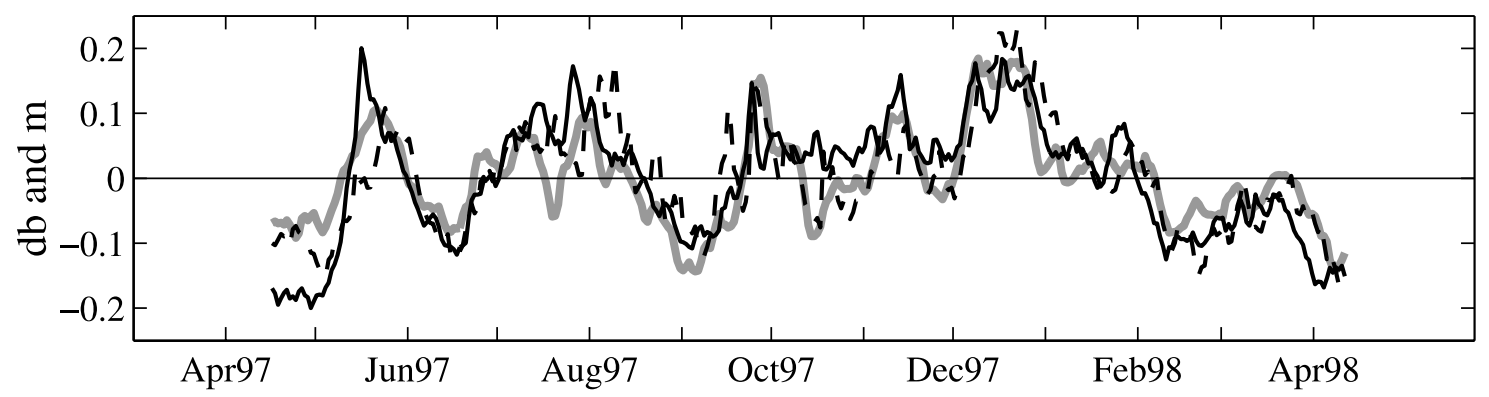

Figure 5. Observed subsurface pressure at Ballenas Channel (thick gray line), NLOM (dashed line), and HYCOM (thin black line) sea level averaged on the $50 \mathrm{~km}$ closest to the continental side of the zonal line at the mouth of the gulf, appearing in Figure 1. The annual cycle has been removed from all time series. 
Table 2. Correlations Between Modeled Surface Transport at the Mouth of the Gulf and in the Northern Gulf, With Near-Bottom Velocities in the Northern Gulf ${ }^{\mathrm{a}}$

\begin{tabular}{cccc}
\hline Period, Depth & NLOM Mouth & HYCOM Mouth & HYCOM NG \\
\hline July 1997 to March $1998,260 \mathrm{~m}$ & -0.41 & -0.39 & -0.48 \\
& -0.73 & -0.61 & -0.72 \\
Nov 1997 to July $1998,317 \mathrm{~m}$ & -0.36 & -0.59 & -0.66 \\
& -0.63 & $-0.92^{\mathrm{c}}$ & $-0.80^{\mathrm{c}}$ \\
\hline
\end{tabular}

${ }^{a} \mathrm{NG}$ denotes northern gulf. Upper number is for daily series, and lower one for monthly averages.

${ }^{\mathrm{b}}$ This refers to depth of observed currents during each period.

${ }^{\mathrm{c}}$ Value is significant at a $99 \%$ confidence level.

coherences at periods greater than 65 days for the NLOM surface transport and the currents $80 \mathrm{~m}$ above the bottom during the first period. The phase for the first non-zero frequency band is close to $180^{\circ}$, indicating a negative correlation between the modeled and observed series. Similarly, the HYCOM transport in the northern gulf also shows significant coherences with the currents $23 \mathrm{~m}$ above the bottom during the second period (see Figure $7 \mathrm{~b}$ ). The phases for the significant coherences during the second period are also close to $180^{\circ}$. Coherences between the NLOM and the velocity observations for the second period (currents at $317 \mathrm{~m}$ ) showed only one significant coherence for periods around 60 days, whereas the corresponding coherences between HYCOM and the observations of the first period (currents at $260 \mathrm{~m}$ ) showed no significant coherences at low frequencies. These two coherence plots (not shown) correspond to the lowest correlations for NLOM and HYCOM, appearing in Table 2.

[20] Figure 7 shows that coherence between transport at the mouth and currents in the NGC occur at periods around 60 days. Therefore it seems appropriate to consider monthly averages of these quantities. Figure 8 shows that the NLOM surface transport at the mouth and the HYCOM surface transport in the northern gulf have a stronger negative correlation with near-bottom velocities in the NGC on a monthly timescale, as compared to the daily series. Correlation coefficients between monthly surface transport and velocities are also listed in Table 2 . All these correlations are statistically significant at a $95 \%$ confidence level, assuming that the nine points are independent. This is probably not a bad assumption given the intraseasonal scales that characterized the 1997-1998 EN event [Strub and James, 2002a]. This is further supported by the fact that the autocorrelation functions of monthly modeled transports and observations drop significantly at lag one. Note that the monthly modeled surface transports (dashed lines in both panels of Figure 8) are somewhat different for both models. The NLOM gives the most prominent peak in December 1997 with other peaks in July and September 1997 and March 1998, whereas the HYCOM gives the most prominent peaks in May and July and a smaller one in December. The time variability of the HYCOM transport appears to reproduce better the two pulses in surface transport found by Strub and James [2002a] near the mouth of the gulf at a latitude of $21.4^{\circ} \mathrm{N}$.

\subsection{Hydrographic Observations During July 1997}

[21] In early July 1997, an hydrographic survey was conducted at stations along a section from the northeast of Angel de la Guarda Island to the coast of Sonora (see
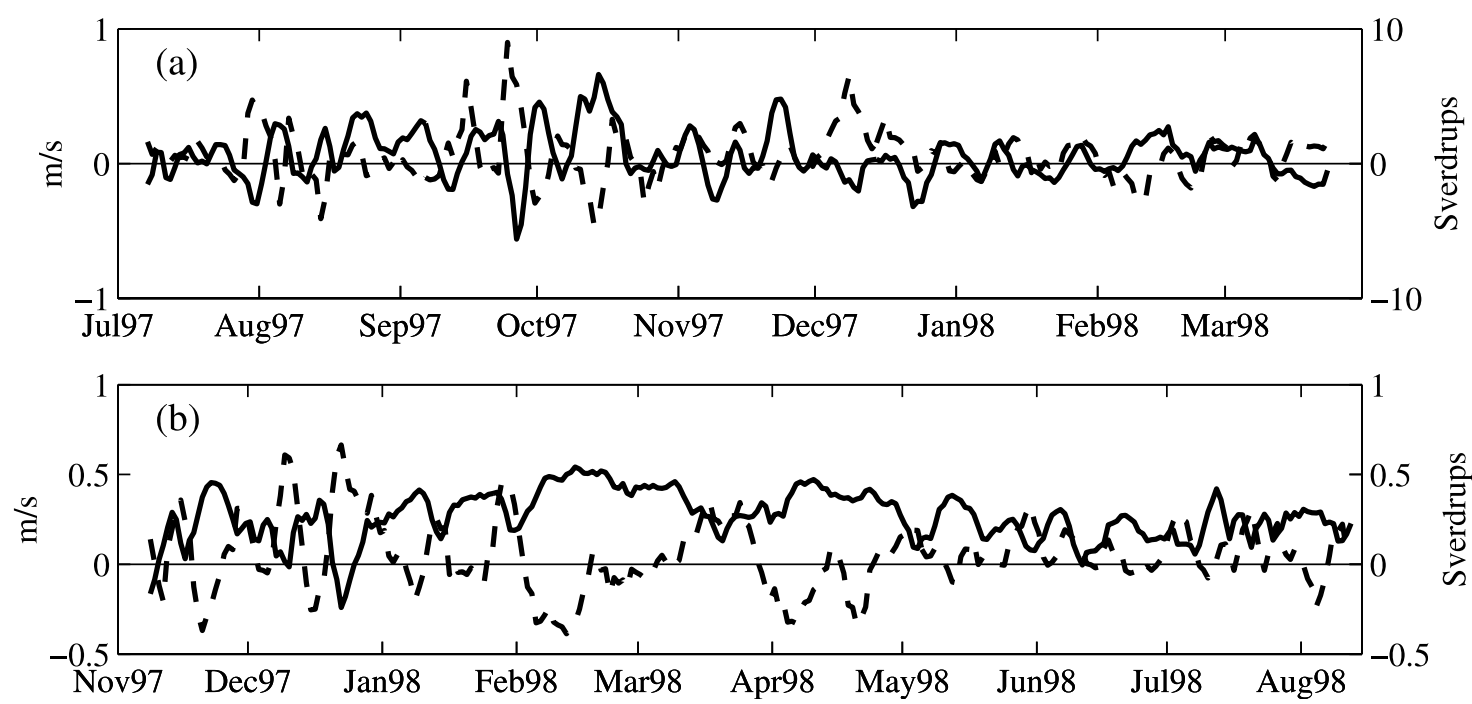

Figure 6. (a) Observed velocity at $260 \mathrm{~m}$ depth ( $80 \mathrm{~m}$ above the bottom) at a sill in the northern gulf (continuous line), and NLOM meridional surface transport at a zonal line at the mouth of the gulf (dashed line). Positive velocities and transports are toward the head of the gulf and northward, respectively. (b) As in Figure 6a, except that the observed velocity is at $317 \mathrm{~m}(23 \mathrm{~m}$ above the bottom) and the modeled transport is from HYCOM in the northern gulf. Note the different time axes in both panels. 

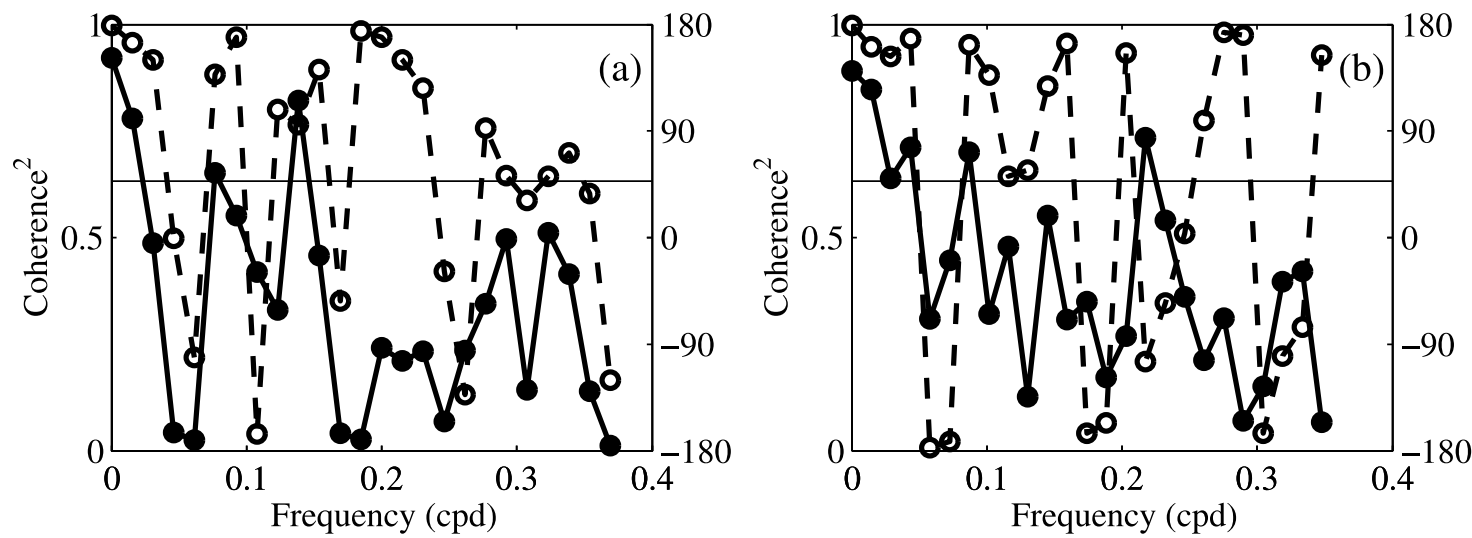

Figure 7. (a) Coherences squared (solid circles) and phases (open circles) between the time series appearing in Figure 6a. The horizontal line marks the value of coherence that is significantly different from zero at a 95\% confidence level. (b) As in Figure $7 \mathrm{a}$, but for the series appearing in Figure $6 \mathrm{~b}$. Positive phases are for observations leading the models.

Figure 1). Figure 9 shows the TS diagram for these data, together with historical data from six cruises in the same region of the gulf during the same season (July to September). The historical data include moderate and weak El Niño events, weak La Niña events as well as a neutral period (see Table 3), as determined by the seasonal (trimester-based) classification of the Climate Prediction Center of the National Center for Environmental Prediction (see http:// www.cpc.ncep.noaa.gov/products/analysis monitoring/ ensostuff/ensoyears.html). On the basis of a subjective analysis of SST along the equator in the western tropical Pacific, this classification divides seasonal events into seven categories: strong, moderate and weak warm events (denoted by $\mathrm{W}+, \mathrm{W}$, and $\mathrm{W}-$, respectively), a neutral event $(\mathrm{N})$, and the corresponding cold events (denoted by $\mathrm{C}+, \mathrm{C}$, and C-). According to this classification system, July 1997 constituted part of a strong warm episode (see Table 3 ).

[22] Figure 9 clearly shows that with the exception of near-surface waters (i.e., the low salinity bulge centered around $\sigma_{t}=24.5$ ), water in this region of the northern gulf tended to be more saline than in other years. In particular, there is practically no deep water below 35 . Water with salinities below 35 is nominally taken as subtropical, subsurface water coming from the Pacific Ocean. Nearly
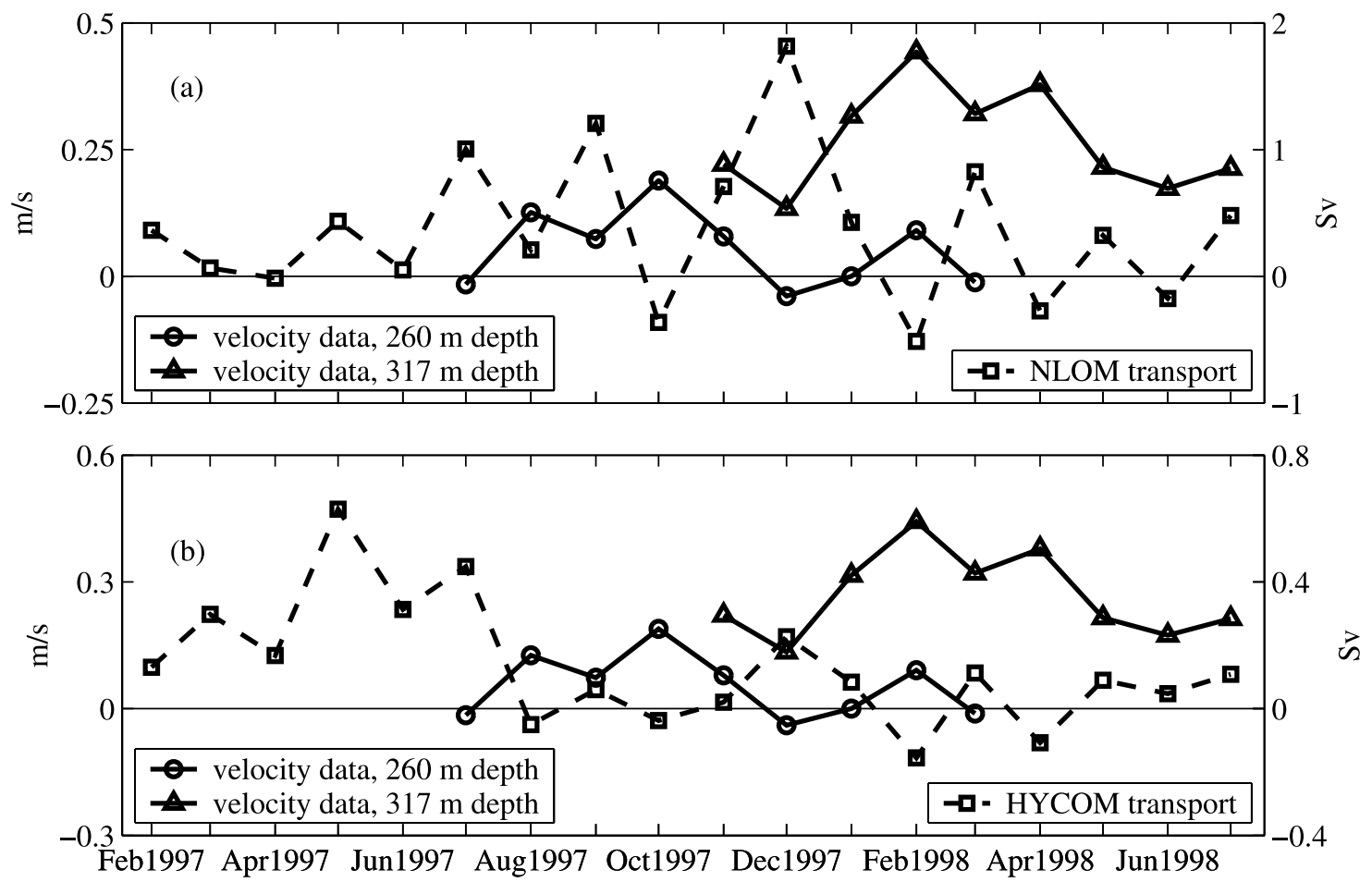

Figure 8. (a) Monthly averages of the observed velocities in the northern gulf and NLOM surface transport at the mouth of the gulf. (b) As in Figure 8a, but for the surface transport corresponding to HYCOM in the northern gulf. 


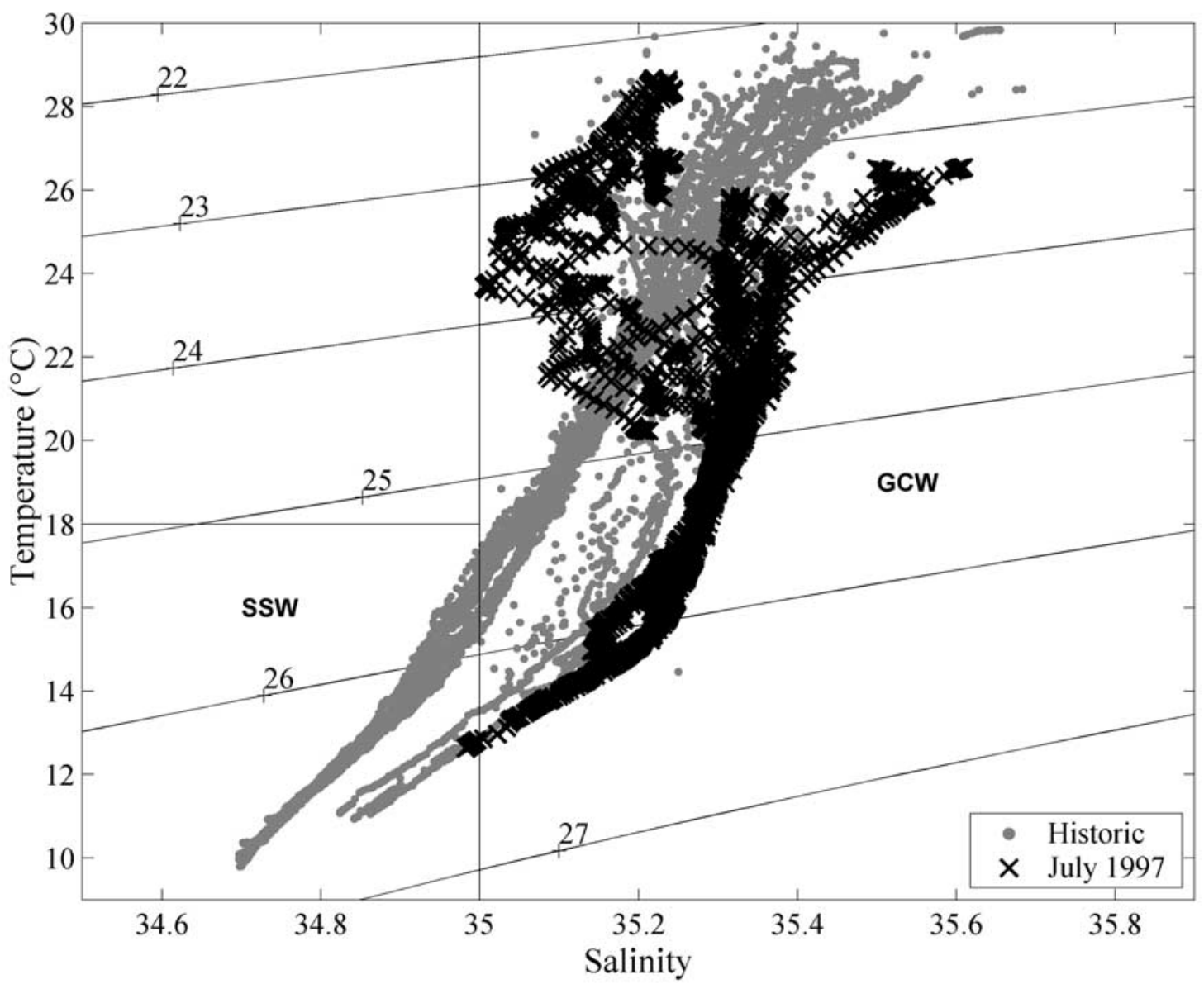

Figure 9. T-S diagram of hydrographic data taken during July 1997 (black crosses) and historical data taken in the same region of the northern gulf and during the same season (gray dots). GCW refers to Gulf of California water, and SSW refers to subsurface, subtropical water.

all of the water present is Gulf of California water (GCW), which is above 35 according to the classification of TorresOrozco [1993]. It is important to remember that salinity decreases with depth in the NGC, and the largest salinities are usually at the surface. During July 1997, deeper waters were also significantly warmer and lighter than in other years. In order to emphasize this fact, we plotted historical data only down to $379 \mathrm{db}$, which was the maximum pressure attained in the July 1997 hydrographic survey. Since near-surface salinities in the NGC are practically always well above 35 [Berón-Vera and Ripa, 2002], the bulge of relatively low salinity, near-surface water (i.e., that centered around a $\sigma_{t}=24.5$ in Figure 9) is anomalous. This is most likely due to the intrusion of tropical surface water that has been mixed with GCW in its passage through the island region.

\section{Discussion}

[23] Several authors have discussed the effects of El Niño in the Gulf of California. Robles and Marinone [1987] observed lower salinities in the Guaymas-Sta. Rosalía line during the 1957 and 1983 El Niño events. They attributed the lower salinities to tropical surface water, entering as far up as the Guaymas Basin from the Pacific Ocean. They also suggested that higher-salinity water, coming from the north, sank and flowed southward beneath the tropical surface water. Bray [1988b] observed higher salinities in the northern gulf, and speculated that such higher salinities could be due to enhanced evaporation during El Niño events. Using hydrographic observations, Lavín et al. [1995] proposed, among other possibilities, that the larger volumes of high salinity water during El Niño years could be due to a trapping of the waters in the northern gulf by the increased presence of tropical surface water. This trapping, in turn, would increase the residence time (and hence the salinity) of the water in the northern gulf.

[24] In this study, we have shown that two different largescale numerical models, with and without data assimilation as well as different forcings, hindcast a similar anomalous

Table 3. Cruise Information for the Data Used in Figure $9^{\text {a }}$

\begin{tabular}{ccc}
\hline Cruise Month and Year & Number of Casts & Episode Strength $^{\mathrm{b}}$ \\
\hline Aug 1957 & 9 & $\mathrm{~W}$ \\
Sept 1971 & 23 & $\mathrm{C}-$ \\
Sept 1986 & 43 & $\mathrm{~W}-$ \\
July 1990 & 2 & $\mathrm{~W}-$ \\
Aug 1990 & 2 & $\mathrm{~W}-$ \\
July 1997 & 16 & $\mathrm{~W}+$ \\
July 2000 & 1 & $\mathrm{~N}$ \\
\hline
\end{tabular}

${ }^{\mathrm{a}}$ First two cruises were done with bottles.

${ }^{\mathrm{b}}$ This denotes warm and cold episode strength. See text for details. 
surface transport (upper $100 \mathrm{~m}$ ) into the gulf, with a corresponding anomalous transport out of the gulf in the underlying layer during the 1997-1998 El Niño. Although the two models show a different vertical structure of the near-surface transport for an 8-year mean, they both agree during the 1997-1998 El Niño event. Furthermore, the anomalous surface transport extends into the northern gulf during El Niño. We have also shown that the anomalous surface, northward transport from both models is negatively correlated with observed near-bottom inflow in the northern gulf. The observed near-bottom inflow constitutes part of the two-layer exchange between the northern and southern gulf and the Pacific Ocean (LG). Our results are consistent with the inhibition of the deeper inflow into the northern gulf by the anomalous surface transport into the gulf. This reduction of the deep inflow would, therefore, be accompanied by an overall reduction of the normal exchange between the northern and southern parts of the gulf during the 1997-1998 El Niño. This, in turn, could increase the residence time of the Gulf of California water in the northern gulf, thereby producing an overall increase in salinity in the region. Moreover, the anomalous presence of high salinity, lower density water all the way to the bottom, as observed during July of 1997, strongly suggests that Gulf of California water sank and occupied depths at which fresher (less than 35) and cooler water is normally present. Indeed, the flow at $80 \mathrm{~m}$ above the bottom shows the flow to be weak, with a tendency to flow toward the south during July (see Figures 6a and 8).

[25] Both models also hindcasted a deep anomalous transport into the gulf below $1000 \mathrm{~m}$ during the 19971998 El Niño. Deep inflows into the gulf were observed by Mascarenhas et al. [2004] during May 1992 and November 1997, both of which were El Niño years (see their Figure 4). Moreover, the horizontally averaged geostrophic velocity profile during November 1997 (i.e., the horizontal average of the November 1997 section, appearing in Figure 4 of Mascarenhas et al. [2004]) shows a deep inflow below $1000 \mathrm{~m}$. Consistent with this deep inflow, there is a large vertical deflection of the deep isopycnals during November 1997 (R. Castro, personal communication, 2005). These deep flows could also be related to the slope flows modeled by Clarke and Van Gorder [1994] at ENSO timescales. A more definite conclusion regarding the existence of this deep inflow will have to await more observations and modeling results. Even if the mean, anomalous deep inflow at the mouth during the 1997-1998 El Niño event turned out to be a transient feature during November, we do not believe it is affecting our results. Since the deepest sill at the entrance of the northern gulf is $600 \mathrm{~m}$, this inflow must return in the overlying layer, a fact that is consistent with the outflow below $100 \mathrm{~m}$ during El Niño, as shown in Figure 4. Our results, however, depend on the transport of the surface layer, which is unlikely to be affected by the deep inflows. Since the anomalous surface and deep transports are into the gulf, there is no reason to believe that the anomalous surface transport is related to a compensating flow for the deep inflow.

[26] The sea level at the entrance of the gulf, as hindcasted by the two models, is closely correlated with SSP well inside the northern gulf. However, the modeled sea level close to the continent is somewhat better correlated to the observed SSP (Table 1). In addition, there is a lag of about 6 days between the modeled sea level along both coasts of the mouth of the gulf. This is consistent with the sea level variability, entering the gulf as coastally trapped waves that propagate around the gulf. The lower correlation with the sea level, averaged all across the mouth of the gulf, could then be due to averaging sea level with slightly different phases. On the other hand, the lower correlation with the sea level on the $\mathrm{BC}$ side could be related to a degradation (e.g., by scattering) of the coastally trapped waves as they propagate around the gulf.

[27] Unfortunately, we do not possess current observations for periods before July. However, T/P SSH and modeled sea level (see Figure 2b) at the mouth, as well as the T/P SSH data presented by Strub and James [2002a], show high sea level at the mouth of the gulf as early as May, with a corresponding peak in the northern gulf (see Figure 5). Furthermore, the modeled transports (see Figure 8), together with the anomalies of observed transport [Strub and James, 2002a], also show northward transport as early as May. The high, near-bottom salinities observed in July (see also the salinity time series at $260 \mathrm{~m}$ depth in Figure 13 of LG), therefore, could have been building up since the first manifestations of El Niño in the gulf. Note that this mechanism, producing higher near-bottom salinity waters due to a reduction and/or downward shift of the normal nearsurface outflow, could operate without the need for increased evaporation during El Niño events, as suggested by Bray [1988b]. All of these results support the ideas proposed by Robles and Marinone [1987] and Lavín et al. [1995], ideas based solely on hydrographic observations.

[28] Hydrographic observations taken during 1997-1998 provide further evidence of the effect of El Niño on the exchange of the northern gulf. Filonov and Tereshchenko [2000] found lower surface salinities just to the north of Manzanillo $\left(19^{\circ} 3^{\prime} \mathrm{N}, 104^{\circ} 20^{\prime} \mathrm{W}\right)$ as early as June 1997 . The anomalies persisted until January of 1998. Castro et al. [2000] also found lower surface salinities by 0.1 to 0.2 at the mouth of the gulf in November 1997. Figure 9 also shows lower surface salinities, as compared to other years, in the northern gulf during July 1997. Therefore the anomalous surface water that entered the gulf as a result of El Niño was of lower salinity and cannot explain the larger salinities found near the bottom in the northern gulf. These larger near-bottom salinities must have originated in the northern gulf itself as a result of the reduced and/or vertically shifted exchange described previously. The mechanism by which salty Gulf of California waters achieved greater depths is unknown and beyond the scope of the present data. However, it should be pointed out that the incoming surface water from the Pacific is warmer and less saline during El Niño. It is consequently lighter than the Gulf of California water, which can certainly flow out beneath the incoming water from the Pacific Ocean.

[29] The negative correlation between northward surface transport at the mouth and in the northern gulf with the deep inflow in the northern gulf is for roughly 60-day or larger periods. These periods are typical of intraseasonal waves observed along the eastern Pacific coast and enhanced during other El Niño events [Spillane et al., 1987; Kessler et al., 1995]. They are also consistent with the relatively high frequency oscillation that modulated the 1997-1998 


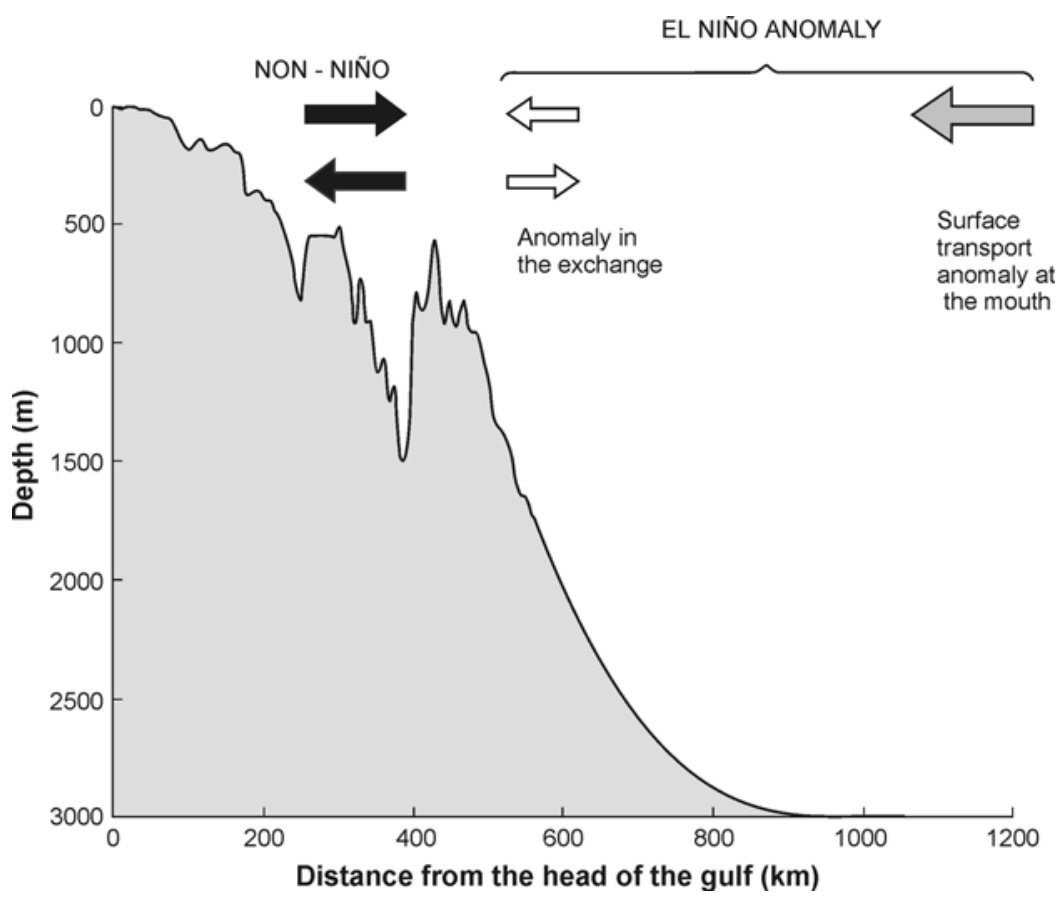

Figure 10. Conceptual picture of the perturbation to the exchange in the northern gulf during the 19971998 El Niño event. Black, solid arrows represent the normal exchange of the northern gulf, and white arrows represent the transport anomaly encountered during El Niño. The gray arrow represents the anomalous surface transport at the mouth of the gulf during El Niño. The bathymetry for $x<562 \mathrm{~km}$ is the maximum depth across the gulf, and the sill around $430 \mathrm{~km}$ represents San Esteban sill at the entrance to the northern gulf.

El Niño event in the tropical Pacific [McPhaden, 1999]. It actually appears that the oscillations observed in sea level, in the surface transport, and in the near-bottom flow also affected salinity and temperature in the near-bottom waters. LG showed a time series and monthly averages of temperature and salinity at $260 \mathrm{~m}$ depth ( $80 \mathrm{~m}$ above the bottom) at a mooring very close to that used here (see their Figure 13). The time series spans a period similar to that appearing in Figure 6a. These time series show high salinities (above 35) and temperatures at the beginning of the time series in early July (consistent with Figure 9), as well as relative temperature and salinity (also reaching values above 35 ) maxima in January 1998. These maxima coincide, albeit possibly with some delay, with the two maxima in the SSH observed in the eastern equatorial Pacific [Strub and James, 2002b], with two of the maxima in the northward transport across the mouth of the gulf, as well as with a weakening or reversal of the near-bottom northward velocity (see Figure 8). In particular, the salinity maximum in January corresponds to a strengthening of the El Niño event in the northern gulf, as measured by the SST anomaly [Lavin et $a l ., 2003$ ] as well as a maximum poleward transport into the gulf [Strub and James, 2002a] (see also Figure 8).

[30] Figure 10 presents a simplified picture of the perturbations of the exchange in the northern gulf during El Niño events. This illustration shows the normal exchange of the northern gulf (black, solid arrows) and the anomaly in the exchange during El Niño events (white arrows). The anomaly is given as the El Niño exchange, minus the exchange encountered during "normal" conditions. This anomaly could be realized as a result of two different scenarios. In one scenario, the normal exchange would be reduced; therefore there would be less outflow of near-surface, high salinity Gulf of California water and less inflow of nearbottom, relatively cold and fresh water from the Pacific Ocean. In the second case scenario, an anomalous surface flow of low salinity, tropical water into the northern gulf and a downward shift (i.e., to greater depths) of the normal outflow of Gulf of California water could explain the anomaly. This latter scenario also implies a reduction or halting of the deep inflow from the Pacific Ocean into the northern gulf. The second scenario would also explain the higher near-bottom salinities observed during July 1997 and January 1998.

[31] The normal exchange in the northern gulf ensures a continuous supply of nutrient-rich, near-bottom water. This supply may be responsible, at least partially, for the relatively large productivity of the northern gulf. The significant reduction in primary productivity in the gulf, as observed by the SeaWiFS (Sea-viewing Wide Field-of-view Sensor) satellite during late 1997 and 1998 [Lluch-Cota et al., 1999], could have been due to a reduced supply of nutrient-rich, near-bottom water.

\section{Concluding Remarks}

[32] The 8-year mean velocity hindcasted by two different high-resolution, large-scale numerical models at the mouth of the gulf is in good qualitative agreement with the available observations of the flow in the mouth (Figure 3). We have shown that both models predict an anomalously high sea level and surface northward transport 
at the mouth and in the northern part of the Gulf of California during the 1997-1998 El Niño event. These results corroborate those obtained by Strub and James [2002a], who used T/P sea surface height data. Moreover, the HYCOM hindcasted surface transport appears to reproduce better the time variability of the satellite estimated transport obtained by Strub and James [2002a]. The models further predicted that the transport beneath the surface layer at the mouth was also anomalous (outflowing) during the 1997-1998 El Niño. The modeled sea level at the mouth correlates well with observed SSP located well inside the northern gulf, although the NLOM does not include that part of the gulf. This highlights the importance of the Pacific Ocean in determining the low-frequency sea level variability inside the northern gulf, at least during the 1997-1998 El Niño event. Furthermore, the modeled surface transport in the upper $100 \mathrm{~m}$ at the mouth and in the northern gulf correlates negatively with the near-bottom velocities observed at a sill in the northern gulf. Since near-bottom velocities measured at that sill in the northern gulf are an indication of the inflow coming from the southern gulf, we conclude that the anomalous surface transport, which occurred during the 1997-1998 El Niño, trapped waters in the northern gulf thereby increasing their residence time and/or shifted the normal, near-surface outflow toward the bottom. These two possible scenarios produced high salinity, nearbottom water, which peaked during July 1997 and January 1998. This higher near-bottom salinity water does not imply a higher evaporation. The normally higher salinity water, which usually occupies the upper part of the water column, could have sunk due to the presence of lower salinity water entering the gulf during El Niño. The negative correlation between modeled surface transport and near-bottom velocities in the northern gulf is centered around 60-day periods, which were typical of the high-frequency oscillations that characterized the 1997-1998 El Niño event.

[33] There is also evidence that lower salinity water from the Pacific entered the northern gulf near the surface. It remains to be determined to what extent this advection is responsible for the anomaly in SST in the northern gulf [Lavin et al., 2003], and how much can be attributed to the increased residence time of the waters in the northern gulf. Longer residence times of the waters in the northern gulf would increase the salinity as well as the temperature of the water during the summer.

[34] The perturbations in the exchange are due to the strong signal of the 1997-1998 El Niño, coming from the Pacific, although it is not clear whether the influence of the Pacific Ocean will be as noticeable during normal or La Niña conditions. Therefore it remains to be determined whether these or other models will also be successful in comparing conditions at the mouth of the gulf to those in the northern gulf under non-El Niño conditions.

[35] Acknowledgments. The authors wish to thank the crew of the $\mathrm{B} / \mathrm{O}$ Francisco de Ulloa for their help in acquiring the observations. S. Sánchez, J. García, F. Miranda, S. Ramos, A. Ledo, B. Pérez, and I. González were most helpful during the field work. A. Reséndiz provided support in Bahía de los Ángeles. We are grateful to the Secretaría de Marina for allowing us to use the July 2000 cruise data. Thanks are extended to Subrahmanyam Bulusu (COAPS/FSU) who kindly provided the TOPEX/Poseidon data, and to Rubén Castro for sharing his unpublished results. Helpful comments by Miguel Lavín and English revisions by Andrea Spears are greatly appreciated. NLOM simulations were conducted by Tammy Townsend at the NRL in Stennis Space Center, and HYCOM simulations were performed by Joe Metzger (NRL) on the IBM SP3 computer at the Army Research Laboratory, Aberdeen, Maryland, under the Department of Defense High Performance Computing Modernization Program. Our gratitude is extended to Joe Metzger and Harley Hurlburt (NRL) for their great help with the models. This is a contribution to the 6.1 project, Dynamics of Low Latitude Western Boundary Currents (grant to Harley Hurlburt), and to the 6.2 project, Coastal Ocean Nesting Studies (grant to Patrick Hogan), both funded by the Office of Naval Research (ONR). Parts of this work, including the acquisition of data, were funded by CONACyT, grant G33464-T, of the Mexican Government.

\section{References}

Badan-Dangon, A., M. C. Hendershott, and M. F. Lavín (1991), Underway Doppler current profiles in the Gulf of California, Eos Trans. $A G U$, 72(209), 217-218.

Baumgartner, T. R., and N. Christensen Jr. (1985), Coupling of the Gulf of California to large-scale interannual climatic variability, J. Mar. Res., 43, $825-848$.

Berón-Vera, F. J., and P. Ripa (2002), Seasonal salinity balance in the Gulf of California, J. Geophys. Res., 107(C8), 3100, doi:10.1029/2000JC000769.

Bleck, R. (2002), An oceanic general circulation model framed in hybrid isopycnic-Cartesian coordinates, Ocean Modell., 37, 55-88.

Bray, N. A. (1988a), Thermohaline circulation in the Gulf of California, J. Geophys. Res., 93(C5), 4993-5020.

Bray, N. A. (1988b), Water mass formation in the Gulf of California, J. Geophys. Res., 93(C8), 9223-9240.

Castro, R., A. S. Mascarenhas, R. Durazo, and C. A. Collins (2000), Seasonal variation of the salinity and temperature at the entrance of the Gulf of California, Mexico, Cienc. Mar, 26(4), 561-583.

Clarke, A. J., and S. Van Gorder (1994), On ENSO coastal currents and sea level, J. Phys. Oceanogr., 24(3), 661-680.

Collins, C. A., N. Garfield, A. S. Mascarenhas, M. G. Spearman, and T. Rago (1997), Ocean currents across the entrance to the Gulf of California, J. Geophys. Res., 102(C9), 20,927-20,936.

Emery, W. J., and R. E. Thomson (1997), Data Methods in Physical Oceanography, 634 pp., Elsevier, New York.

Enfield, D. B., and J. S. Allen (1980), On the structure and dynamics of monthly mean sea level anomalies along the Pacific Coast of North and South America, J. Phys. Oceanogr., 10, 557-578.

European Centre for Medium-range Weather Forecasts (ECMWF) (1994), The description of the ECMWF/WCRP Level IIIA Global Atmospheric Data Archive, report, 72 pp., Reading, UK.

Filonov, A., and I. Tereshchenko (2000), El Niño 1997-98 monitoring in mixed layer at the Pacific Ocean near Mexico's west coast, Geophys. Res. Lett., 27(5), 705-707.

Godin, G. (1972), The Analysis of Tides, Univ. of Toronto Press, Toronto, Ont., Canada.

Kessler, W. S., M. J. McPhaden, and K. M. Weickmann (1995), Forcing of intraseasonal Kelvin waves in the equatorial Pacific, J. Geophys. Res., 100(C6), 10,613-10,631

Lavín, M. F., G. Gaxiola-Castro, J. M. Robles, and K. Richter (1995), Winter water masses and nutrients in the northern Gulf of California, J. Geophys. Res., 100(C5), 8587-8605.

Lavín, M. F., E. Palacios-Hernández, and C. Cabrera (2003), Sea surface temperature anomalies in the Gulf of California, Geofis. Int., 42(3), 363375.

Lluch-Cota, D., et al. (1999), Las pesquerías y El Niño, in Los Impactos de El Niño en México, edited by V. O. Magaña R., pp. 137178, SEP-CONACYT, Mexico City, Mexico.

López, M., and J. García (2003), Moored observations in the northern Gulf of California: A strong bottom current, J. Geophys. Res., 108(C2), 3048, doi:10.1029/2002JC001492.

Mascarenhas, A. S., Jr., R. Castro, C. A. Collins, and R. Durazo (2004), Seasonal variation of geostrophic velocity and heat flux at the entrance of the Gulf of California, Mexico, J. Geophys. Res., 109, C07008, doi:10.1029/2003JC002124.

McPhaden, M. J. (1999), Genesis and evolution of the 1997-98 El Niño, Science, 283, 950-954.

Metzger, E. J., H. E. Hurlburt, J. C. Kindle, R. C. Rhodes, G. A. Jacobs, J. F. Shriver, and O. M. Smedstad (1998), The 1997 El Niño in the NRL Layered Ocean Model, in 1998 NRL Review, pp. 63-71, Nav. Res. Lab., Washington, D. C.

Metzger, E. J., L. Zamudio, H. E. Hurlburt, and P. J. Hogan (2003), A Hurricane Juliette generated coastally trapped wave in the HYbrid Coordinate Ocean Model (HYCOM), Eos Trans. AGU, 84(52), Ocean Sci. Meet. Suppl., Abstract OS21K-10.

National Oceanic and Atmospheric Administration (1986), ETOPO5 digital relief of the surface of the Earth, Data Announce. 86-MGG-07, Natl. Geophys. Data Cent., Washington, D. C. 
Rhodes, R. C., et al. (2002), Navy real-time global modeling system, Oceanography, 15(1), 30-44.

Robles, J. M., and S. G. Marinone (1987), Seasonal and interannual thermohaline variability in the Guaymas Basin of the Gulf of California, Cont. Shelf Res., 7, 715-733.

Smedstad, O. M., H. E. Hurlburt, E. J. Metzger, R. C. Rhodes, J. F. Shriver, A. J. Wallcraft, and A. B. Kara (2003), An operational eddy resolving $1 / 16^{\circ}$ global ocean model nowcast/forecast system, J. Mar. Syst., 40$41,341-361$

Spillane, M. C., D. B. Enfield, and J. S. Allen (1987), Intraseasonal oscillations in sea level along the west coast of the Americas, J. Phys. Oceanogr., 17(3), 313-325.

Strub, P. T., and C. James (2002a), Altimeter-derived surface circulation in the large-scale NE Pacific gyres: Part 2. 1997-1998 El Niño anomalies, Prog. Oceanogr., 185-214.

Strub, P. T., and C. James (2002b), The 1997-1998 oceanic El Niño signal along the southeast and northeast Pacific boundaries-An altimetric view, Prog. Oceanogr., 439-458.

Subrahmanyam, B. (1998), A study of the Indian Ocean circulation using satellite observations and model simulations, Ph.D. dissertation, 213 pp., Dep. of Oceanogr., Univ. of Southampton, Southampton, UK.
Torres-Orozco, E. (1993), Análisis volumétrico de las masas de agua del Golfo de California, M.S. thesis, 80 pp., Cent. de Invest. Cient. y Educ. Super. de Ensenada (CICESE), Ensenada, Baja California, Mexico.

Zamudio, L., H. E. Hurlburt, E. J. Mertzger, and O. M. Smedstad (2002), On the evolution of coastally trapped waves generated by Hurricane Juliette along the Mexican West Coast, Geophys. Res. Lett., 29(23), 2141, doi:10.1029/2002GL014769.

Zamudio, L., E. J. Metzger, H. E. Hurlburt, and P. J. Hogan (2003), On the monthly variability in the Gulf of California, Eos Trans. AGU, 84(52), Ocean Sci. Meet. Suppl., Abstract OS31D-02.

M. López, Departamento de Oceanografía Física, Centro de Investigación Científica y Educación Superior de Ensenada (CICESE), Km 107 Carretera Tijuana-Ensenada, Ensenada, B.C., Mexico. (malope@cicese.mx)

F. Padilla, Estación de Investigación Oceanográfica de Ensenada, 2a Zona Naval, Boulevard Costero y Sanginés S/N, Zona Centro, Ensenada, B.C., Mexico. (fpadilla@cicese.mx)

L. Zamudio, Naval Research Laboratory, Stennis Space Center, MS 39529, USA. (luis.zamudio@nrlssc.navy.mil) 